\title{
Recent advances in permanent magnet brushless DC motors
}

\author{
BHIM SINGH \\ Department of Electrical Engineering, Indian Institute of Technology, Hauz \\ Khas, New Delhi 110016, India \\ e-mail: bsingh@ee.iitd.ernet.in
}

\begin{abstract}
This paper deals with the latest developments in Permanent Magnet Brushless DC (PMBLDC) motor drives. A comprehensive account of the stateof-the-art on types of construction of the motor, closed loop controllers in position, speed and current/torque control and recent trends in inverters, sensors etc. are given. Techniques for mechanical sensors elimination are discussed in detail. Special efforts made to reduce torque ripples, noise and vibrations are described. The impact of microelectronics through integrated chips used in the control of PMBLDC motor drives is given. The increasing applications of this drive due to improved performance and its cost reduction are also enlisted.
\end{abstract}

Keywords. PMBLDC motor; sensors; controllers; sensorless operation; torque pulsations.

\section{Introduction}

Permanent Magnet Brushless DC (PMBLDC) motors are increasingly being used in a wide spectrum of applications such as domestic equipments, automobiles, information technology equipment, industries, public life appliances, transportation, aerospace, defence equipment, power tools, toys, vision and sound equipment and medical and health care equipment ranging from microwatts to megawatts ${ }^{1-24}$. It has become possible because of their superior performance in terms of high efficiency, fast response, light weight, precise and accurate control, high reliability, maintenance free operation, brushless construction, high power density and reduced size. Recent developments in PMBLDC motor technology in terms of availability of high performance rare earth PM materials, varying motor constructions such as axial field, radial field, package type, rectangular fed, sine fed motors, improved sensor technology, fast semiconductor modules, low cost high performance microelectronics devices, new control philosophy such as robust, adaptive, fuzzy, neural AI based controllers, have been a boon to their widespread use in the large speed ranges from few revolutions to several thousand revolutions per minute (rpm). They have been proven most suitable for position control in machine tools, robotics and high

NB: Citations in this paper are not in our usual format 
precision servos, speed control and torque control in various industry and process control applications $7,8,21-24$.

Inspite of being one of the best, the PMBLDC motor has faced many hurdles to come to its present stage in terms of cost, torque ripples, noise, vibrations, reduced reliability due to the large number of components, operational constraints such as temperature rise etc. Continuous efforts have been made to overcome these problems on different aspects of this drive. The PMBLDC motor drive is undoubtedly quite a big mission in itself; this paper concentrates on the recent advances in PMBLDC motors in terms of motor construction, closed loop controllers, semiconductor power modules, sensors and their reduction, torque ripple minimization, impact of microelectronics, cost reduction and potential applications.

\section{Latest developments in the PMBLDC motors}

Permanent magnet (PM) excitation has been used in place of $d c$ excitation in different electric machines such as $d c$ machines, synchronous machines and new PMBL machines such as PM stepper motors, hybrid stepper motors and PMBLDC motors. High cost of PM materials has been a major bottleneck for use and development of these electric machines. Gradual growth of better PM materials, improved manufacturing technology, varying nature of construction of these motors to suit specific applications have brought them at a level where they are considered one of the best motors available nowadays. PM machines have a wide spectrum but this paper is restricted to PMBLDC motors.

Presently PM materials used in PMBLDC motors are classified in the following three broad categories ${ }^{8-10}$, namely Alnico (Al-Ni-Co-Fe), Ceramics also include ferrites and rare-earth materials such as samarium-cobalt ( $\mathrm{Sm}-\mathrm{Co})$, neodymium-iron-boron ( $\mathrm{Nd}-\mathrm{Fe}-\mathrm{B})$. Alnico and ferrites have long been used in the development of PM motors as they are cheap and easily available. Rare-earth PM materials, namely SmCo, are used nowadays because of the high energy density caused by its high residual flux density, coercive force and low temperature coefficient. $\mathrm{NdFeB}$ is considered one of the best PM materials presently since it offers much higher residual flux density and coercive force. However, its only drawback is the temperature limit. Continuous efforts are being made to overcome this and it is hoped that this will enable PMBLDC motors to attain higher efficiencies and lower sizes along with other advantages.

PMBLDC motors may be classified into different categories such as number of phases, radial or axial field, cageless or with cage bars, surface mounted PMs or buried magnets, sinusoidal or rectangular fed motors etc. Some of them are briefly discussed in this section.

\section{$2.1 \quad$ Number of phases}

PMBLDC motors are developed in single phase in low power $(<50 \mathrm{~W})$ for tube axial fans to cool electronics equipments 25 . They are manufactured in two phase construction for home appliances such as solar PV fed refrigeration system, servo control etc. Most of the medium and high power rating motors are designed in three-phase construction similar to conventional ac motors. In some electric vehicles ${ }^{22-24}$ and megawatt rating 
motors for submarine propulsion etc., designers have compelling reasons to increase the number of phases to five, six or more in order to reduce the per phase power handling requirements.

\subsection{Radial and axial field motors}

Most of the motors in the market are radial field type (cylindrical or salient pole construction). However, the axial field motors have some advantages over the conventional radial field construction in terms of power density, torque to inertia ratio, peak torque, less magnet weight, low inductance, short winding turns, compact design etc. ${ }^{6,8}$. Axial field motors are designed in package, disk and sandwich type construction and have no iron in the rotor, resulting in low inertia. Axially directed magnetic field from rotor magnet interacts with radially directed currents in these axial field motors. The magnets are encapsulated in resin or plastic. Because of their construction, they are considered most suitable for robotics, computer equipments, machine tools etc. ${ }^{8}$.

Radial field motors are also designed with varying desired flux linkage waveforms such as sinusoidal or trapezoidal, different shapes and positions of magnets in the rotor such as buried or surface mounted etc. They are widely used since stator design is similar to conventional ac synchronous or induction motors. Figure 1 shows the typical cross-sections of these two types of popular PMBLDC motors.

\subsection{Shape and location of PM in rotors}

Permanent magnets are placed in the rotor in PMBLDC motors ${ }^{6,8}$. In axial field type of motors, the magnets are encapsulated in resin or plastic in disc form as shown in figure 1a. These magnets are placed in such a manner that induced back emf are either sinusoidal or trapezoidal waveforms. In radial field motors, the magnets are placed in different form such as surface mounted for low speed motors and interior radially oriented or interior tangentially oriented in high speed PMBL motors. Figure 2 shows such rotor geometries. They are also designed to achieve sinusoidal or trapezoidal back emfs depending upon applications.

\subsection{Sinusoidal and rectangular fed motors}

PMBLDC motors are designed to have either sinusoidal or trapezoidal (excited) induced back emfs ${ }^{8,26-32}$. Sinusoidal excited motors are fed with sinusoidal polyphase currents similar to conventional synchronous motors for ripple-free torque with unity power factor for constant torque operation below base speed with frequency control and having leading currents to affect field weakening for constant power operation. Maximum speed of operation is restricted with demagnetization caused by armature reaction and mechanical construction. Magnetic saliency on rotor with reluctance torque helps to achieve wide speed range of constant power operation. Trapezoidal excited motors need polyphase balanced rectangular currents with 120 electrical degree width and adjustable magnitude and direction. Constant flux interaction with constant amplitude polyphase currents develops ripple free torque similar to conventional $d c$ motor with electronic commutation. Because 


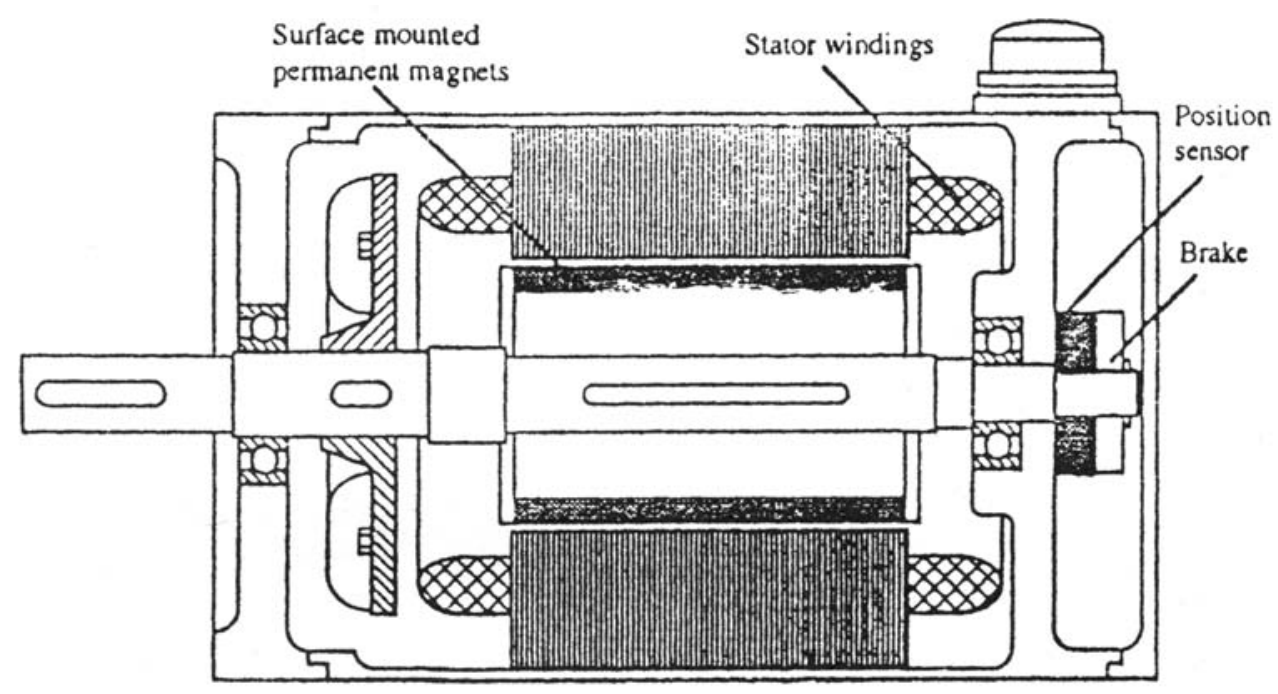

b

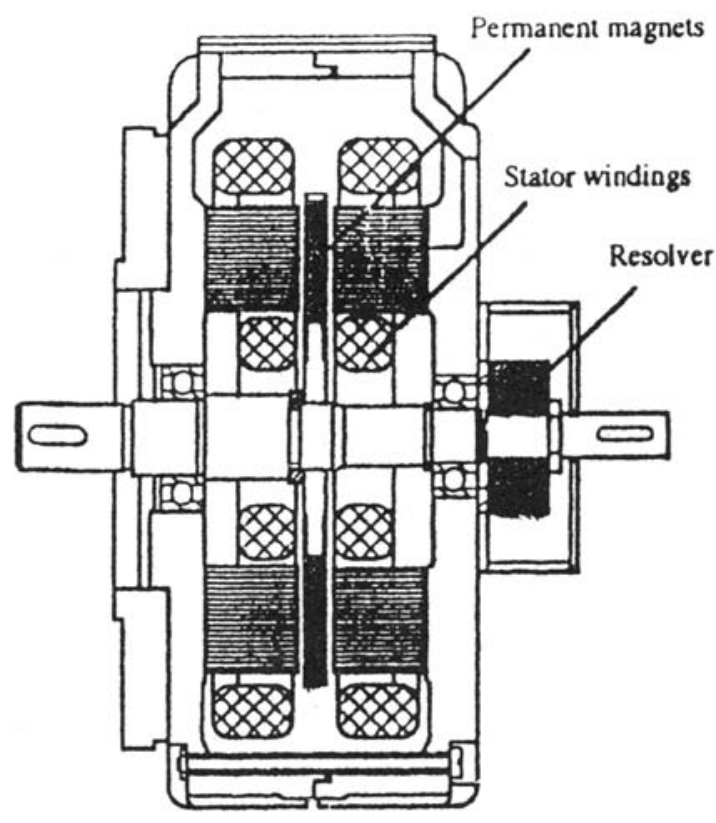

a

Figure 1. Cross-sections of two types of PMBLDC motors (a) Axial field motor, (b) radial field motor. 


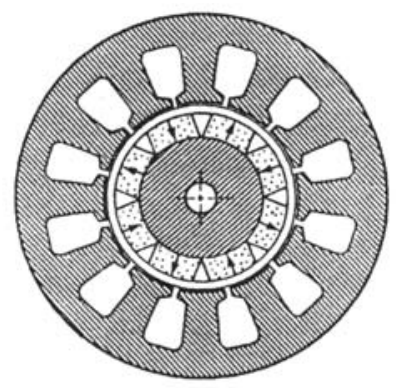

(a)

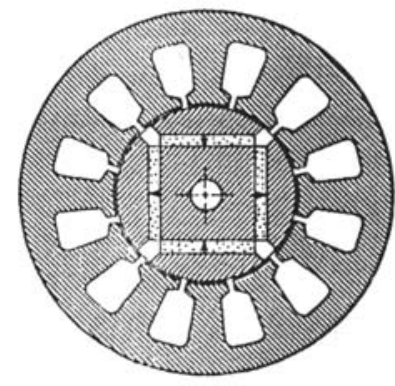

(b)

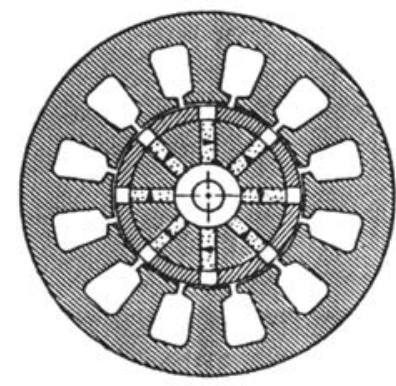

(c)

Figure 2. Rotor geometries of PMBLDC motors. (a) Surface mounted, (b) interior radiallyoriented, and (c) interior tangentially oriented magnets.

of these rectangular currents they are also called switched PM motors, brushless $d c$ motors and electronic commutated PMBLDC motors.

Figure 3 shows the ideal current waveforms for these two types of motors. Position sensors requirement is accordingly changed to realize these ideal current waveforms in the motor windings in self synchronous control mode.

\section{Closed loop controllers}

Irrespective of sinusoidal or trapezoidal excitation, PMBLDC motors are used for position control, speed control and torque control in motion control applications ${ }^{3,8}$. Figure 4 shows a typical position closed loop control with inner speed and current loops. For speed control system outer position loop is not required and speed reference is the command signal. Torque control is incorporated in high performance motion control through closed loop regulation of phase currents in synchronization with shaft position feedback. In the majority of PMBLDC motors, torque is linearly related to currents and torque command maps into current commands with only a simple proportionality constant. In some typical cases, a nonlinear mapping is required between torque and current commands. The

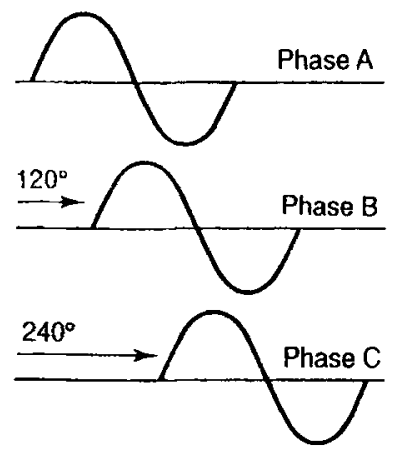

(a)
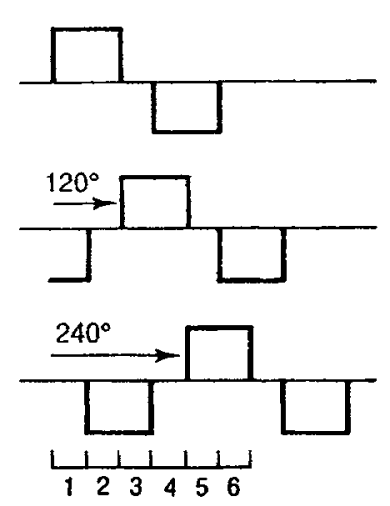

(b)

Figure 3. Ideal current excitation waveforms of (a) sinusoidal and (b) trapezoidal motors. 


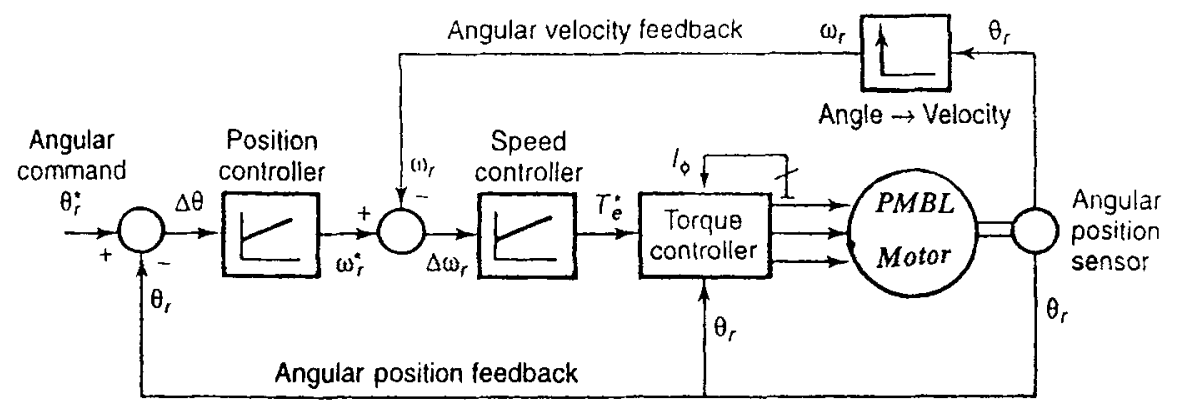

Figure 4. Block diagram of closed loop position control with speed and current loops of of PMBLDC motor drive.

constant power operation of PMBLDC motor drive is extended through field weakening control techniques which also requires another command signal for torque to current mapping. Current regulation in the phase windings of PMBLDC motors either in sinusoidal or rectangular manner is carried out using current controlled voltage source inverter(VSI). PWM, hysteresis and predictive current controllers are used to issue the switching signals to the devices of the inverter to realize winding currents close to command currents. Speed control is generally achieved by using a speed feedback and speed command through speed controller which outputs a command signal for torque controller. Position control is implemented through position feedback and position command using position controller. The output of the position controller is the speed command for inner speed loop. Both position and speed closed loop controllers are realized using wide varying closed loop controllers such as PI (proportional-integral), PID (proportional-integral-derivative) ${ }^{8}, \mathrm{SMC}$ (sliding mode controller) ${ }^{33-35}$, adaptive controllers ${ }^{36}$, fuzzy based control ${ }^{8,19}$ and neural based controllers ${ }^{8}$.

These classical (PI or PID) controllers or advanced closed loop controllers such as SMC, fuzzy and neural network-based ones are implemented using DSP, microcontroller and specific application integrated chip (ASIC) for speed and/or position control. Many manufacturers have developed ASICs for typical applications of PMBLDC motors.

\section{Recent developments in inverters and converters}

PMBLDC motors are invariably fed from variable frequency inverters to provide electronic commutation. At small ratings, MOSFET-based VSIs are used to achieve ideal current control with reasonable high switching frequency. In medium rating drives, IGBT-based VSIs are used to feed PMBLDC motors. GTO-based inverters are used in high power rating PMBLDCM drives because of their self-commutating feature and improved current control. In medium and high power rating PMBLDC motors, an input unity power factor rectifier with PWM current control is used to achieve regulated $d c$ link and regenerative feature of the PMBLDC motor drive. Classical PI/PID and feedforward closed loop controllers are used for the control of front end converters. It improves the power quality of the $a c$ mains in terms of reduced harmonics and unity power-factor in both the directions of power flow. 
Recently MOSFET/IGBT-based VSIs are used in module forms to achieve compact design of the drive. Power MOS ICs are used to control small rating PMBLDC motors which has integrated microelectronics for control and power amplifier to excite the motor. Moreover, their gate drives are also used in module form with all protective and intelligent control features. In some typical applications (residential commercial blower), they are made so compact that these are fitted inside the motor housing ${ }^{8}$.

\section{Latest trends in sensors}

In the control of PMBLDC motors, position, speed and current sensors are essentially required to regulate the phase currents in synchronization with rotor position ${ }^{3,4,8}$. Moreover, sometimes, terminal voltage sensors are also required to estimate either position or speed. Voltage sensors are also needed to regulate $d c$ bus voltage during braking or for front end converter control. In some typical attempts, flux sensors and torque sensors are also used in the precise control of these motors. Basic role of these sensors are already discussed in closed loop control of PMBLDCM drive in $\S 3$. In the following section, the recent trends in sensors and their function are briefly discussed.

\subsection{Position sensors}

The rotor flux position in PMBLDC motors is defined by the mechanical angle of rotation, which is achieved from some form of rotor position sensors. Rotor flux position is required for phase current synchronization and rotor position is also required for position control. Rotor position is directly sensed using position sensors or indirectly estimated using other measured parameters. Hence, rotor position sensing is indispensable in current-controlled PMBLDC motor drives.

Rotor position is sensed using resolvers, inductive modular absolute system (IMAS) ${ }^{37}$, hall effect position sensor, magnetoresistors ${ }^{38}$, electronics and optical encoders, synchros and tachsyn ${ }^{39}$. The tachsyn is an airgap reluctance sensitive 3-phase alternator with PM field and trapezoidal output waveforms. It is used for position and velocity sensing and signal outputs are analog. They are available in 4,6 and 8 pole configurations. The encoders are characterised by number of pulses per revolutions (PPR) and nowadays they are available in several thousands PPR. Interfacing ICs are also available to convert these sensor signals to digital form to feed digital processors used for intelligent control of PMBLDCM drives.

Indirect position sensing is achieved by estimating the rotor position using other measured parameters such as currents and voltages etc. There are many techniques for rotor flux position estimation which are much detailed in the next section.

\subsection{Speed/velocity sensors}

In the PMBLDC motor drive, speed or velocity signals are essentially required for speed control loops in position controlled drives and speed feedback for speed controlled drives. Speed measurement is carried out either using speed transducers/sensors or estimated 
using the rotor position information either obtained through direct position sensing or through estimation.

In general $d c$ tachogenerators and brushless tachogenerators are used to sense motor speed. They provide an analog $d c$ voltage signal which is proportional to shaft speed. The polarity of this voltage signal in both types of tachogenerators results in the direction of rotation. Nowadays rotor velocity/speed is estimated more accurately by using high resolution position sensors or estimated rotor flux position. Sometimes, these sensors are different from the position sensors used for electronic commutation.

\subsection{Current sensors}

Fast torque control in high performance PMBLDC motor drives is implemented through closed loop regulation of phase winding currents in synchronization with rotor flux position information. Closed loop regulation of winding currents is realized through PWM or hysteresis current controllers of CC-VSI over the reference desired currents and sensed winding currents. Therefore, the sensing of winding currents becomes indispensable in PMBLDC motor drives.

The current sensing is generally carried out using hall effect current sensors. They detect the magnitude and direction of currents and are integrated to provide sensitive and accurate current sensing. Very fast response (less than 1 microsecond) and accurate current sensors are available from different manufacturers (ABB, LEM etc.) in wide range of current sensing (fractions of amperes to kiloamperes). These hall effect current transducers have galvanic isolation of several kilovolts which is a very desired requirement of these drives in high rating. Generally in 3-phase motors two current sensors are required and thirdphase current is estimated from other two-phase currents in star connected motors. These current sensing requirements for current regulated rectangular fed PMBLDC motor drive are typically reduced to a single current sensor in the $d c$ link of the inverter. Current shunt resistors with low power dissipation are often used as the current sensor in low power drives for cost effectiveness. In the modern power devices such as MOSFET/IGBT a current sensing feature is provided by many manufacturers which also dispenses with the use of extra current sensors in the control of the inverter/converter feeding the PMBLDCM.

\subsection{Voltage sensors}

Terminal voltage sensing in modern advanced PMBLDC motor drives is required to estimate the rotor position and speed for the control, resulting in mechanical sensorless drive with a view to reduce size, cost, maintenance and enhanced reliability. Voltage sensing is also required to regulate $d c$ bus voltage during braking or for control of front end converter used for regenerative feature in high rating drives.

Terminal voltage sensing is carried out by using electronic isolation amplifier (AD202 Analog Devices make etc.) and hall effect voltage sensors (ABB make etc.) with galvanic isolation. In small rating drives, voltage is sensed using high valued resistor potential dividers to reduce the cost of the drive. Sometimes, induced voltage in the motor windings is achieved using special windings such as search coils etc. However, ac mains voltages for the control of front end converter are sensed using the potential transformers. 


\section{Sensors elimination and reduction}

Recent trends in sensors, their requirement and types of available sensors are already discussed in $\$ 5$. However, some of these sensors in PMBLDC motor drive may be reduced from the view point of size, cost, maintenance and reliability. Typically mechanical rotor position and speed sensors have the drawbacks of increasing the number of connections between motor and controller, increased interference, limitation in accuracy of sensors due to environmental factors such as temperature, humidity, vibrations etc., increased friction and inertia and additional space in motor housing. Because of these problems recently there has been wide interest and developments in the techniques for elimination of mechanical rotor position/speed sensing by estimating the rotor position and speed using sensed currents and voltages ${ }^{40-57}$. Moreover, the number of voltage and current sensors may be reduced through using intelligent processors for the control of inverter feeding PMBLDC motors. Various techniques for these sensors elimination and reduction are briefly discussed in the following section.

\subsection{Mechanical sensors elimination}

One of the most recent developments in PMBLDC motor drives has been the rapid evolution of new techniques for eliminating the rotor angular position sensor. Elimination of the shaft-mounted position sensor is a very desirable feature in a number of applications since this sensor is one of the most expensive and fragile components in this drive. Some of the position sensorless schemes are classified in brief.

\subsection{Back EMF based position estimation}

The most common methods of rotor flux position sensing is based on deriving the back emf signals. There are many methods for rotor position estimation based on the back emf and are briefly discussed below.

6.2a Direct back EMF detection: This method is quite popular for rectangular fed PMBLDC motors. In these PM motors, particular phase winding is excited for $2 / 3$ of each electrical period and ideally there is always one phase which is not excited. The direct sensing of back emf of unexcited phases in sequence is used to generate discrete rotor position signal for current synchronization with rotor flux. It has been applied to many industrial applications including disk drives ${ }^{46}$, compact stereo players 41,42 and room air conditioners 43

6.2b Estimation of back EMF: This method is applied to both sinusoidal fed and rectangular fed PMBLDC motors. This method is based on the reconstruction of the back emf by using voltage equation of the motor $(e=v-i R-L \mathrm{~d} i / \mathrm{d} t)$. Reconstruction of the back emf involves either simulating this equation with operational amplifier ${ }^{46}$ or solving this equation in on-line digital processor normally used for control ${ }^{52}$. In this method, the 
terminal voltage and line current are measured directly and the above equation is used to achieve back emf and rotor position.

\subsection{Third harmonic voltage detection based position estimation}

In star-connected PMBLDC motors, the third harmonic voltage is measured between the star point and an artificial star point created by three high-value resistors which are connected to the motor terminals. Such a voltage gives six zero crossings in the 3-phase motor and results in rotor position for current synchronization with rotor flux.

\subsection{By monitoring current or computation of the phase inductance}

The basic concept of this method is that the rate change of current in a phase winding of the motor depends on the incremental inductance which is rotor position dependent. This phase winding inductance variation with rotor position is used to estimate the rotor position for electronic commutation of the inverter. This current sensing model for rotor position estimation is used by Lin et al ${ }^{50}$.

\subsection{Injecting diagnosis signal to the stator winding}

This method uses a PWM carrier frequency and inductance bridge to measure the rotor flux path reluctance. The method operates on a bridge principle by monitoring the inductance difference in two phases, and is sensitive to small variations in reluctance.

\subsection{Observer methods}

In these methods, an observer reconstructs the rotor position which is directly measurable. Basically all these methods use the sensed phase and/or line currents to perform on-line compensation to derive the rotor position. A number of observer methods such as Kalman filter technique, discrete time observer, state observer and stator flux estimation method current and the voltage based observer method ${ }^{56-57}$ as well as improved different types of motors, are reported.

\subsection{By a special windings electromagnetic devices}

A number of methods based on special winding such as search coils or an electromagnetic device ${ }^{58}$ are used to sense the rotor position. The electromagnetic device consists of pickup coils around a special stator made of magnetically nonlinear material. The pick-up coils are excited by a high frequency sinusoidal current. The device detects the phase of the second harmonics component of the induced voltage in the pick-up coils.

\subsection{Monitoring switching states in the inverter}

This method is applied to rectangular fed PMBLC motor and ON/OFF states of inverter switching devices are used for rotor position estimation ${ }^{51}$. The method is based on a 
motor with trapezoidal back-emf. The rotor flux position is obtained on the basis of the conducting state of free-wheeling diodes in an open phase at a particular time.

In most of these methods, the rotor speed/velocity is estimated by using the time derivative of rotor position angle or by measurement of the period during the transition of alternating rotor position.

\subsection{Elimination/reduction of current and voltage sensors}

Intensive work is carried out to reduce the current and voltage sensors in the PMBLC motor drive to reduce the cost and enhance reliability. Normally two current sensors are required in 3-phase star connected motors, a technique used to estimate the 3-phase winding currents only using one current sensor in the $d c$ link and switching states of the inverter devices. Since, in the intelligent inverter control, device-switching patterns are available in the processor, the 3-phase winding currents signals are constructed using measured $d c$ link current and switching status of the inverter devices. Similarly, one voltage sensor is used at the $d c$ link and three-phase terminal voltages are derived using the same switching states of the inverter devices.

For rectangular fed PMBLDC motor drives, current sensors can be eliminated entirely using current sensors embedded in three of the six inverter switches ${ }^{59}$. MOS gated devices such as MOSFET and IGBTs in integrated modules from different manufacturers are available which incorporate current sensors integrated into monolithic power devices.

\section{Torque pulsations, noise, vibration and their reduction}

Any divergence from ideal conditions either in the motor (design factors) or in the power inverter feeding PMBLDC motor drive (current waveforms) results in undesired torque pulsations ${ }^{60-68}$. The torque pulsation in PMBLDCM drive causes speed oscillations, excitation of resonances in mechanical portions of the drive causing acoustic noise and visible vibration patterns in high precision machines. Pulsating torque in PMBLDC motors is basically in form cogging torque generated by interaction of the rotor magnetic flux with stator magnetic reluctance variation and ripple torque generated by the interaction of stator current mmfs with rotor magnets. Ripple torque is due to mutual or alignment torque caused by current mmf with rotor flux distribution and reluctance torque caused by current mmf with rotor reluctance variations. In rectangular fed PMBLDC motor, the fringing fields at the rotor pole edges cause deviations from ideal trapezoidal emf waveform and currents are also not strictly rectangular resulting in dip of the torque magnitude up to $25 \%$ of rated torque 67 .

Torque pulsations are minimized by two broadly classified techniques, namely improved motor designs and active control schemes. Improved design techniques for pulsating torque minimization include skewing, fractional slot winding, short pitch winding, increased number of phases, airgap windings, adjusting stator slot opening and wedges ${ }^{68}$, rotor magnetic design through magnet pole arc, width and positions ${ }^{67}$. Improved design and manufacturing of the PMBLDCM with refined and computer-aided techniques such as $\mathrm{CAD}, \mathrm{CAM}$ have resulted in reduction in torque pulsations. 
However, active control techniques for pulsating torque minimization include adaptive control technique ${ }^{8,67}$, preprogrammed current waveform control, selective harmonics injection techniques, estimators and observers, speed loop disturbance rejection, high speed current regulators, commutation torque minimizations ${ }^{67,68}$ and automated self commissioning schemes ${ }^{67}$.

\section{Field weakening}

Field weakening of PMBLDC motors has become quite demanding for achieving high speed operation in constant power applications such as electric vehicles etc. ${ }^{8,69}$. For speeds above base speed, the rotational emf increases rapidly and constant power operation cannot be maintained at high speeds. The amplitude of back emf (line to line) increases linearly with speed and becomes more than the $d c$ link voltage of the inverter. Eventually the current controller saturates losing its ability to force the desired reference currents into the motor phases.

Reasonable torque production may be attained by advancing the phase angle of the excitation transition points relative to back emf. As this angle is advanced, current in on coming phase is given a controlled time interval to build up before the back emf increases and chokes off further current growth. This concept is illustrated through figure 5. Figure 5a shows the concept of advance angle $(\alpha)$ in back emf and current of a particular phase winding of rectangular fed PM motor for $2 / 3$ period excitations $\left(120^{\circ}\right)$. However, this concept is also applicable for current excitation of $180^{\circ}$. The resulting effects of this advance angle excitation on torque-speed characteristics of the PMBLDCM are shown in figure $5 \mathrm{~b}$. This concept is used in both sinusoidal and rectangular fed motors to extend the speed range as constant power drive. This control aspect can give at the most, the speed range $3: 1$. This speed range may only be extended to $7: 1$ or more by proper designing of the motor such as axially laminated PM reluctance motor.
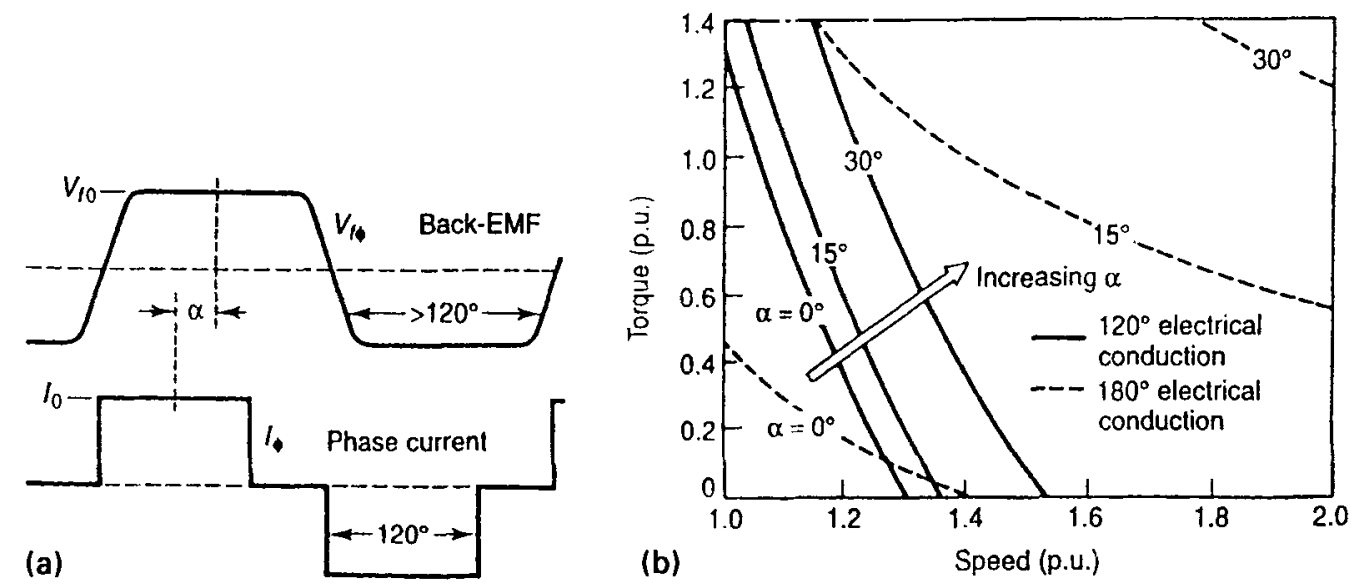

Figure 5. (a) Typical back emf and phase current waveforms of rectangular fed PMBLDC motor drive with advance angle. (b) Typical torque-speed curves of rectangular fed PMBLDC motor drive with advance angle control. 


\section{Impact of microelectronics on PMBLDC motor drive}

Improved and intelligent control techniques for the PMBLDCM drive are implemented through advanced technology in integrated electronic circuit chips ${ }^{70}$. ASICs (specific application integrated chips) are developed by many manufacturers namely LM621 by National Semiconductors Limited, (Si9985CY) by Silconix, SA/SE/NE5570 by Phillips etc. for the PMBLDCM drives. Moreover, sensorless operation of PMBLDC motors, adaptive control, torque pulsation minimization etc are realized through micro controllers, DSP and single chip microcomputers. Reduced cost of manufacturing of VLSI has made it possible to design dedicated ASICs for such complex and intelligent control and providing compact, reliable, low cost and effective controller for PMBLDCM drives ${ }^{70}$. For many dedicated applications, power and control are integrated in the same MOS ICs for low power PMBLDCM drives.

\section{Application issues of PMBLDC drives}

PMBLDC motors are attractive in drive applications which benefit from high efficiencies as compared to induction motor and switched reluctance motors. Sinusoidal-fed PMBLDC motors are considered superior to rectangular-fed PMBLDC motors for achieving the wide high speed constant power speed range ${ }^{8}$. The positive characteristics of PMBLDC motor discussed earlier make them highly attractive for a number of applications, a few of which are given here.

\subsection{Servo actuators}

High power density, fast dynamic response, smallest size and weight with rare earth magnet (Nd Fe-B or SmCo) of PMBLDC motors have made them the best suited candidates in machine tool servos, robotics actuators drives and dual tandem electromagnetic actuators (EHA) 21 .

\subsection{Commercial residential speed control applications}

PMBLDC motors drives are used in a wide range of commercial and residential applications such as domestic appliances, heating, ventilating and air conditioning equipment due to their highest possible efficiencies. The speed control ability of compressors and blowers is able to provide operation at their high efficiency. The physical integration of controller electronics in the motor body itself is able to make them most suitable for low power $(0.5 \mathrm{hp})$ blowers and low power $(50 \mathrm{~W})$ tube axial fans for cooling the electronics equipment ${ }^{25}$.

\subsection{Automotive applications}

The efficient variable speed feature with low volume of PMBLDC motors has made them most suited for electric vehicles ${ }^{24}$ such as electric cars, buses, pallet trucks etc. and traction ${ }^{22}$. PMBLDC motors with interior magnet geometry and magnetic saliency are 
capable of providing wide speed range constant power characteristics at high efficiency to match these automotive applications.

\subsection{High power industrial and propulsion drives}

High power (1.1 MW), six-phase PMBLDC motors are considered best-suited for direct drive marine propulsion application to replace the $d c$ motor drive with a saving of $40 \%$ in weight, length and volume. PMBLDC motors upto $2 \mathrm{MW}$ power rating and speed of $4000 \mathrm{rpm}$ are used in land and marine propulsion systems and industrial pumping.

With high efficiency and high power density, the demand for PMBLDC motor drives is increasing and is expected to continue for high performance servos, commercial residential products, computer industry, information technology, propulsion systems, vehicle and traction.

\section{Conclusions}

The latest trend and present status of PMBLDC motor drives have revealed that this drive has great potential for use in a number of applications. The use of new PM materials, latest motor construction technology, intelligent closed-loop control, new types of inverters, sensorless operation, and field weakening have resulted in potential applications and provided a broad prospective to drive-design and application engineers. The methods of torque pulsation reduction have been explored to design PMBLDCM drives to suit highly position-sensitive applications. In view of these new developments, these drives are expected to enjoy a bright future in a larger number of applications of adjustable speed applications requiring high efficiencies and fast dynamic responses such as blowers, compressors, automobiles, vehicle propulsion systems and traction drives.

\section{References}

[1] T Kenjo, S Nagamori 1985 Permanent magnet brushless DC motors (Oxford: Clarendon)

[2] T J E Miller 1989 Brushless permanent magnet and reluctance motor drive (Oxford: Clarendon)

[3] P Pillay (ed.) 1989 Performance and design of permanent magnet AC motor drives. IEEE Industry Applications Society Tutorial Course, IEEE Industry Applications Society Meeting, San-Diego, CA

[4] Y Dote, S Kinoshita 1990 Brushless servomotors fundamentals and applications. Oxford: Clarendon

[5] Y Dote 1990 Servo motor and motion control using digital signal processors. (Englewood, Cliffs, NJ: Prentice Hall)

[6] D C Hanselman 1994 Brushless permanent magnet motor design (New York: McGrawHill)

[7] J F Gieras 1996 Permanent magnet motor drives. Power Electronics, Drives \& Energy Systems' 96 , Tutorial, Indian Inst. Technol., Delhi

[8] B K Bose (ed) 1997 Power electronics and variable frequency drives - Technology and applications. (New York: IEEE Press) 
[9] D Weinmann, G Nicoud, F Gallo 1984 Advantages of permanent magnet motors. Proc. of Drives/Motors/Controls-84, Brighton, UK, pp 113-120

[10] L M C Mhango 1989 Benefits of Nd-Fe-B magnet in brushless DC motor design for aircraft applications. Proc. of 4th International Conference on Electrical Machines and Drives, IEE Conf. Pub. No. 310, pp 76-79

[11] K J Binns 1994 Permanent magnet drives; the state of the art. Symposium on Power Electronics, Electrical Drives, Advanced Electric Motor SPEEDAM 94, Taormina, Italy, pp 13-18

[12] M A Rahman, G R Slemon 1985 Promising applications of neodymium, boron and iron magnets in electrical machines. IEEE Trans. Magne. MAG-21: 1712-1716

[13] E Ritchter, T J E Miller, T W Neumann, T L Hudson 1985 The ferrite permanent magnet AC motors - A technical and economical assessment. IEEE Trans. Ind. Appl. IA-21: 644-650

[14] R Hanitsch, C S Park 1990 Novel $10 \mathrm{~W}$ brushless DC motor of the Pankake type (IEE CD No.-324) 4th International Conference on Power Electronics and Variable Speed Drives, pp 435-439

[15] D Pauly, G Plaff, A Weschta 1984 Brushless servo drives with permanent magnet motors or squirrel cage induction motors - A comparison. IEEE IAS Annual Meeting, pp 503-508

[16] D Howe, M K Jenkins, Z Q Zhu 1993 Permanent magnet machines and drives - An integrated design approach. (IEE CP No. 376) IEE Sixth International Conference on Electrical Machines and Drives Oxford, UK, pp 625-630

[17] T S Low, K J Binns 1986 Multistacked imbricated rotors with permanent magnet excitation; Design for new magnetic materials. Inst. Elec. Eng. Proc. B133: 205-211

[18] S Williams 1985 Direct drive system for an industrial robot using a brushless DC motor. Inst. Elec. Eng. Proc. B132: 53-56

[19] M A Jabbar 1996 Disk drive spindle motors and their controls. IEEE Trans. Ind. Electron. 43: 276-284

[20] W L Soong, D A Staton, T J E Miller 1993 Design of a new axially-laminated interior PM motor. IEEE-IAS Annual Meeting Record, pp 27-36

[21] T M Jahns, R C Van Nocker 1990 High performance EHA control using an interior PM motor. IEEE Trans. Aero. Elect. Syst. 26: 534-542

[22] B Sneyers, G Maggetto, J Van Eck 1992 Inveter fed permanent magnet motor for road electric traction. Proc. of ICEM-1992, Budapest, pp 550-553

[23] A R Millner 1994 Multi-hundred horsepower permanent magnet brushless disk motors. Proc. of APEC Conf., pp 351-355

[24] C C Chen, K T Chau, J Z Jiang, W Xia, M Zhu, R Zhang 1996 Novel permanent magnet motor drives for electric vehicles. IEEE Trans. Ind. Electron. 43: 331-339

[25] L Newborough 1990 Electronically commutated DC motor for driving tube axial fans: A cost effective design. Appl. Energy 36: 167-190

[26] G Liu, W G Dunford 1990 Comparison of sinusoidal excitation and trapezoidal excitation of a brushless permanent magnet motor. (IEE CD No 324) 4th International Conference on Power Electronics and Variable Speed Drives, London, pp 446-450

[27] M Allan, I J Kemp, 1993 Commutation strategies for the DC brushless motor. (CP No. 376) Sixth International Conference on Electrical Machines on Drives, Oxford, UK, 133-178

[28] J De La Ree 1990 Performance evaluation of PM machines with quasi-square wave input currents. Elec. Mach. Power Syst. 18: 283-291

[29] C S Berendsen, G Ckampenois, A Bolopion 1993 Commutation strategies for brushless DC motors: Influence on instant torque. IEEE Trans. Power Electron. 8: 231-236 
[30] A Rubaai, R C Yalmanchili 1992 Dynamic study of an electronically brushless DC machine via computer simulations. IEEE Trans. Energy Conversion 7: 132-136

[31] M T Wishart, R G Harley, C Diana 1991 The application of field oriented control to the brushless DC machine. Proc. Euro. Power Electron. Conf., Ferenze, pp 629-634

[32] C L Putta Swamy, B Singh, Bhim Singh 1995 Investigations on dynamic behavior of permanent magnet brushless DC motor drive. J. Elec. Mach. Power Syst. 23: 689-701

[33] C Rossi, A Tonielli 1994 Robust control of permanent magnet motors: VSS techniques lead to simple hardware implementations. IEEE Trans. Ind. Electron. 41: 451-460

[34] G Carrara, D Casini, A Landi, L Taponecco 1991 Sliding mode speed controller for trapezoidal brushless motors. Elec. Mach. Power Syst. 19: 157-169

[35] B Singh, B P Singh, C L Putta Swamy 1995 Modeling of variable structure controlled permanent magnet brushless DC motor: J. Inst. Eng. (India) 75: 183-189

[36] E Cerruto, A Consoli, A Raciti, A Testa 1995 A robust adoptive controller for PM motor drives in robotic applications. IEEE Trans. Power Electron. 10: 62-71

[37] G R Horner, W Freund 1991 A new approach to multi-turn absolute position, velocity and motor commutation signals. Proc. of Drives/Motors/Controls 1991, pp 155-158

[38] C Ferreira, D Belanger, J Vaidya 1987 A magnetic rotor position sensor for brushless permanent magnet motors. Proc. of MOTOR-CON 1987, pp 146-156

[39] J R Luneau 1985 New developments in feedback devices for brushless DC servosystems. Proc. of MOTOR-CON 1985, pp 86-95

[40] R Krishnan, R Ghosh 1987 Starting algorithm and performance of a permanent magnet brushless motor drive with no position sensor. IEEE Power Electron. Syst. Conf. 1987, pp 596-606

[41] N Ertugrul, P Acarnley 1994 A new algorithm for sensorless operation of permanent magnet motors. IEEE Trans. Ind. Appl. 30: 126-133

[42] P P Acarnley, N Ertugrul 1992 Rotor position estimation in PM motors. International Conference on Electrical Machines, pp 1-5

[43] T Endo, F Tajima, H Okuda, 1983 Microcomputer-controlled brushless motor without a shaft-mounted position sensor. International Power Electronics Conference, IPEC, Tokyo, pp 1478-1488

[44] H Hzuka, H Uzuhashi, M Kano, I Endo, K Mohri 1985 Microcomputer control for sensorless brushless motor. IEEE Trans. Ind. Appl. IA-21: 595-601

[45] N Matsui, M Shigyo 1992 Brushless DC motor control without position and speed sensors. IEEE Trans. Ind. Appl. 20: 339-346

[46] B C Kuo, K Butts 1982 Closed loop control of a 3.6 degree floppy-disk drive PM motor by back EMF sensing. 11th Proc. of SIMCSO, Champaign

[47] J Hu, D M Dawson, K Anderson 1995 Position control of a brushless DC motor without velocity measurements. IEE Proc. Elec. Power Appl. 142: 113-122

[48] K J Binns, D W Shimmin, K M Al-Aubidy 1991 Implicit rotor position sensing using motor windings for self-commutating permanent magnet drive system. Inst. Elec. Eng. Proc. B138: 28-34

[49] T Furuhashi, S Sangwongwanich, S Okuma 1992 A position and velocity sensorless control for brushless DC motors using an adaptive sliding mode observer. IEEE Trans. Ind. Elec. 39: 89-95

[50] R L Lin, M T Hu, C Y Lee 1989 Using phase current sensing circuit as the position sensor for brushless DC motor without shaft position sensor. Proc. of IEEE-IECON-1989, Part 1

[51] S Ogasawara, H Akagi 1991 An approach to position sensorless drive for brushless DC motors. IEEE Trans. Ind. Appl. 27: 000-000 
[52] H Watanabe, T Ishii, Fujii DC brushless servo system without rotor position and speed sensor. Proc. IEEE-IECON-1987, Cambridge, MA

[53] R Wu, G R Slemon 1991 A permanent magnet motor drive without a shaft sensor. IEEE Trans. Ind. Appl. 27:00-00

[54] P W Lee, C Pollock 1992 Rotor position detection techniques for brushless PM and reluctance motor drives. IEEE-IAS Annual Meeting Record, pp 448-455

[55] R C Becerra, T M Jahns, M Ehsani 1991 Four quadrant sensorless brushless ECM drive. Proc. of Appl. Power Electron. Conf., pp 202-209

[56] N Matsui, M Shigyo 1990 Brushless DC motor control without position and speed sensors. IEEE-IAS Annual Meeting Record, pp 448-453

[57] N Matsui 1996 Sensorless PM brushless DC motor drives. IEEE Trans. Ind. Electron. 43 : 300-308

[58] D E Hesmondhalgh, D Tipping 1990 An electromagnetic motor integrated position sensor for brushless DC motors, capable of operation at standstill. Proc. of ICEM-1990

[59] T M Jahns, R C Becerra, M Ehsani 1990 Integrated current regulation for brushless ECM drives. IEEE Trans. Power Electron. 6: 118-126

[60] B Ackermann, J H H Janssen, R Sottek, R I Van Steen 1992 New technique for reducing cogging torque in a class of brushless DC motors. Inst. Elec. Eng. Proc. B139: 00-00

[61] H Bolton, R Ashen 1984 Influence of motor design and feed current waveform on torque ripple in brushless DC drives. Inst. Elec. Eng. Proc. B131: 82-90

[62] H Le-Huy, R Perret, R Feuillet 1986 Minimization of torque ripples in brushless DC motor drives. IEEE Trans. Ind. Appl. IA-22: 748-755

[63] Y Murai, Y Kawase, K Ohashi, K Nagatake, K Okuyama 1987 Torque ripple improvement for brushless DC miniature motors. IEEE-IAS Annual Meeting Record

[64] J Y Hung, Z Ding 1993 Design of currents to reduce torque ripple in brushless permanent magnet motors. Inst. Elec. Eng. Proc. B140: 260-266

[65] $\mathrm{T} \mathrm{Li}, \mathrm{G}$ Slemon 1988 Reduction of cogging torque in permanent magnet motors. IEEE Trans. Magn. 24: 2901-2903

[66] F Leonardi, M Venturuni, A Vishmara 1994 Design and optimization of very high torque, low ripple, low cogging PM motors for direct driving optical telescopes. IEEE-IAS Annual Meeting Record

[67] J Holtz, L Springgob 1996 Identification and compensation of torque ripple in high precision permanent magnet motor drives. IEEE Trans. Ind. Electron. 43: 309-320

[68] TM Jahns, W L Soong 1996 Pulsating torque minimization techniques for permanent magnet AC motor drives - A review. IEEE Trans. Ind. Electron. 43: 321-330

[69] B Sneyers, D W Novotny, T A Lipo 1985 Field weakening in buried magnet AC motor drives. IEEE Trans. Ind. Appl. IA-21: 398-407

[70] D Kinniment, P Acarnley, A Jack 1991 An integrated circuit controller for brushless DC drives. Proc. of EPE, Florence, 4: 111-116 